\title{
A UTILIZAÇÃO DO LAZER COMO ESTRATÉGIA PARA INTEGRAÇÃO DE FAMILIARES/ACOMPANHANTES EM ENFERMARIA DE PEDIATRIA ${ }^{a}$
}

\author{
The utilization of leisure as strategy for the integration \\ of relatives/ companion in a pediatric ward \\ La utilización de la recreación como estrategia para integración de \\ familiares/ acompañantes en enfermaría pediatrica
}

Lucila Castanheira Nascimento

Flávia Mendonça Rosa Luiz

\author{
Paula de Siqueira Furquim \\ Paula Saud de Bortoli
}

Ariane Ranzani Rigotti

Silmara Gianoti

\begin{abstract}
Resumo
0 objetivo deste estudo é relatar a experiência de alunos de graduação em Enfermagem na implantação de um projeto de extensão que utiliza o lazer como estratégia de intervenção aos familiares ou outros acompanhantes de crianças hospitalizadas, numa clínica pediátrica de um hospital universitário do interior do estado de São Paulo. As atividades do grupo, que consistem na realização de trabalhos manuais, desenhos, artesanato, relaxamento, costura, oficinas pedagógico-educativas, dentre outras, foram desenvolvidas em dois encontros semanais, com duração mínima de duas horas cada. Trata-se da utilização do lazer não apenas para distração e passatempo, mas também para que, na busca de minimizar eventos negativos decorrentes do processo de hospitalização, os pais, outros familiares e acompanhantes de crianças e adolescentes internados possam se integrar, de forma criativa, ao processo de cuidado destes clientes.
\end{abstract}

Palavras-chave: Pais. Criança Hospitalizada. Atividades de Lazer. Enfermagem Pediátrica.

\begin{abstract}
This study aims to report on undergraduate nursing students' experience in the implantation of an extension project that uses leisure activities as a strategy for intervention for family members or other companions of hospitalized children, at the pediatric clinic of a University Hospital in the interior of Sao Paulo state, Brazil. The group's activities, which involve handwork, drawing, artwork, relaxation, sewing, pedagogical-educational workshops, and others, were accomplished during two weekly meetings of at least two hours each. Leisure is used not only for distraction and pastime, but also, in trying to minimize negative events that result from the hospitalization process, to allow for the creative integration of parents and other relatives and companions of hospitalized children and adolescents into the care process for these clients.
\end{abstract}

\section{Resumen}

La finalidad de este estudio es relatar la vivencia de alumnos de pregrado en la implantación de un proyecto de extensión que utiliza actividades de recreación como estrategia de intervención a los familiares/acompañantes de niños hospitalizados, en la clínica pediátrica de un hospital universitario en el interior del estado de São Paulo. Las actividades del grupo, que abarcan la realización de trabajos manuales, dibujos, artesanía, relajamiento, costura, oficinas pedagógico-educativas, entre otras, se desarrollaron en dos encuentros semanales, con duración mínima de dos horas cada. Se trata de la utilización de la recreación no sólo para distracción y pasatiempo, pero también para que, al tentarse minimizar eventos negativos resultantes del proceso de hospitalización, los padres y otros familiares y acompañantes de niños y adolescentes internados puedan ser integrados, de forma creativa, al proceso de cuidado de esos clientes.

Keywords: Parents. Child, Hospitalized. Leisure activities. Palabras clave: Padres. Niño hospitalizado. Actividades Pediatric nursing. recreativas. Enfermería pediátrica. 


\section{INTRODUÇÃO}

A complexidade dos aspectos que envolvem a hospitalização infantil tem sido amplamente discutida, evidenciando questões relativas ao impacto deste processo tanto na criança como nos demais membros de sua família que também vivenciam mudanças significativas impostas pela doença'.

Durante a internação hospitalar da criança, impõese a necessidade de reorganização da dinâmica da família, o que exige revisão e reavaliação periódicas dos diversos papéis exercidos pelos membros desta unidade familiar. A principal cuidadora, a mãe, na maioria das vezes, ausenta-se do lar para acompanhar o filho doente; com isso, os outros membros da família vivenciam uma nova realidade devida à doença da criança, ou seja, a hospitalização e ausência da mãe, fato que requer readaptação do núcleo familiar. Nesse contexto, todos os membros da família são afetados, fator que influencia diretamente suas relações. Sentimentos como sofrimento e insegurança são potencializados ${ }^{2}$ nos pais, que apresentam ansiedade, tristeza, medo e estresse, nesta fase ${ }^{3}$, sintomas que podem ser minimizados com a aproximação da família ao plano de cuidado. Especificamente, as estratégias que têm sido apontadas, principalmente na Inglaterra, como bastante eficazes para efetivar esta aproximação são a permanência dos pais ou responsáveis com a criança durante a hospitalização e o incentivo da sua participação nos cuidados dispensados aos filhos ${ }^{4}$. Entretanto, na prática assistencial brasileira, nem todas as instituições incorporam a presença da mãe ou responsável ao cuidado da criança ${ }^{5}$, apesar de ser esta uma conquista garantida desde a década de $1990^{(6,7)}$. Desse modo, no Brasil, a aproximação da família ao cuidado da criança hospitalizada ainda é uma etapa a ser alcançada.

Não apenas a permanência dos pais junto aos filhos, mas principalmente o seu envolvimento no tratamento poderá trazer vários benefícios à criança ${ }^{8}$ e aos seus familiares/acompanhantes ${ }^{9}$. Esta prática constitui-se na possibilidade de tornar o processo de hospitalização ativo e dinâmico, além de dar aos pais a oportunidade de engajar-se melhor no cuidado do filho e de obter informações importantes sobre a evolução de sua saúde, o que lhes trará maior segurança e proporcionará diminuição de sentimentos negativos ${ }^{9}$. A literatura aponta a satisfação dos pais quando tal participação e integração são possíveis ${ }^{10}$.

Apesar dos inúmeros benefícios, esta inserção no ambiente hospitalar não é tão simples, devido à necessidade de alterações no ambiente físico e estrutural do hospital, bem como na organização do trabalho ${ }^{5}$; muitas vezes, a relação entre pais e a equipe de trabalho torna-se tensa e conflituosa. Neste sentido, deve-se ressaltar o papel da Enfermagem que, como membro da equipe de saúde, tem potencial para 0 desenvolvimento de habilidades e sensibilidade para olhar de modo integral o binômio criança hospitalizada e pais/ família e identificar 0 apoio e suporte necessários ${ }^{11}$. Assim, devemos dispensar um cuidado holístico à criança doente e não enfocar apenas a perspectiva biologicista; é importante considerar também as necessidades do familiar que permanece junto à criança ${ }^{(2,12,13)}$.

$\mathrm{Na}$ instituição hospitalar, cenário do nosso trabalho e onde se desenvolveu esta experiência, os pais ou outros membros da família e acompanhantes estão, na maioria das vezes, presentes durante a hospitalização da criança. Assim, a ausência de atividades que possam facilitar a inserção de familiares/acompanhantes no processo de hospitalização da criança e minimizar o estresse que ela acarreta motivou-nos a buscar estratégias que fizessem do processo de hospitalização um evento menos traumático, capaz de tornar o dia-a-dia de todos os envolvidos mais humanizado e prazeroso. Ainda no cenário da instituição em questão, observamos que outras atividades são realizadas nesse sentido, como as leituras do Projeto Biblioteca Viva e a Companhia do Riso, voltadas, em grande parte, para as crianças e não para familiares ou acompanhantes. Notamos que, muitas vezes, estes últimos, em busca de formas que proporcionassem lazer à criança, durante sua permanência no hospital, integravam-se às atividades de recreação organizadas para seus filhos ${ }^{5}$.

Com base nestes pressupostos, sentimos a necessidade de estruturar e implantar um projeto de extensão com atividades de lazer voltadas para os pais/ familiares/acompanhantes, visando auxiliá-los no processo de inserção no espaço hospitalar e na integração ao cuidado proposto para suas crianças, durante a hospitalização.

\section{OBJ ETIVO}

Relatar a experiência de alunos de graduação de Enfermagem na implantação de um projeto de extensão que utiliza o lazer como estratégia de intervenção direcionada aos familiares/acompanhantes de crianças hospitalizadas.

\section{O CAMINHO PERCORRIDO}

Trata-se de um relato de experiência, no qual descrevemos como ocorreu a implantação do projeto de extensão "Integrando pais/familiares em enfermaria de pediatria: uma proposta de ação". O local escolhido 
para realização das atividades foi a Clínica Pediátrica do Hospital das Clínicas da Faculdade de Medicina de Ribeirão Preto da Universidade de São Paulo, unidade localizada no campus universitário. Este é um hospital-escola de referência quaternária, situado em um município do interior do estado de São Paulo, o qual presta atendimento médico de emergência, ambulatorial ou de internação programada à população de qualquer região do país.

A Clínica localiza-se no $7^{\circ}$ andar do referido hospital e possui um total de 42 leitos, distribuídos entre as alas A e B. Na Ala A, estão o isolamento respiratório, a enfermaria de escolares e pré-escolares, 0 isolamento protetor e onco-hematologia. A Ala B é constituída por três enfermarias, nas quais há 20 leitos, e também pela Unidade de Terapia Renal Infantil (UTRI). A Clínica conta ainda com duas salas de curativos, posto de enfermagem, sala da diretoria de enfermagem, sala de televisão e refeitório. Especificamente, é neste último espaço da Clínica que desenvolvemos o projeto.

\section{ESTRUTURAÇÃO E DESENVOLVIMENTO DO PROJ ETO DE EXTENSÃO}

0 projeto de extensão foi estruturado e implantado em maio de 2003, sob a coordenação de docente da área de enfermagem pediátrica da Escola de Enfermagem de Ribeirão Preto da Universidade de São Paulo. Foi desenvolvido, inicialmente, por uma aluna de graduação do curso de Enfermagem, na época bolsista do programa Bolsa Trabalho COSEAS/ USP. Posteriormente, além desta bolsista, contamos com a participação de uma bolsista de Iniciação Científica CNPq/PIBIC/USP e de duas voluntárias, também alunas do curso de graduação em Enfermagem, que participaram regularmente das atividades, auxiliando na operacionalização do projeto.

No início das atividades, realizamos reuniões com a aluna responsável para estruturação das atividades a serem desenvolvidas. As demais alunas foram se integrando ao grupo aos poucos, contribuindo para seu fortalecimento. Concomitantemente, promovemos visitas aos familiares e acompanhantes que tinham crianças internadas, a fim de compreender melhor as necessidades desta clientela no ambiente hospitalar e as possíveis intervenções para amenizar o impacto da hospitalização e ainda fazer com que ficassem mais próximos do cuidado da criança. Procuramos, também, manter maior proximidade da equipe de saúde, especialmente de Enfermagem, para sensibilizá-la a reconhecer a importância do projeto.
As reuniões entre as alunas e a professora responsável eram mensais, visando ao acompanhamento, avaliação e reestruturação das atividades, e procurando atender às sugestões feitas pelos próprios acompanhantes, no decorrer do projeto.

As atividades eram desenvolvidas duas vezes por semana, com duração mínima de duas horas cada; delas, participavam, em média, de quinze a vinte pessoas, especialmente mães. Num primeiro momento, as alunas integrantes do projeto visitavam as crianças, seus familiares e acompanhantes nas enfermarias, assim como nas demais dependências da Clínica, anunciando sorridentes que a atividade ia começar. Após apresentação, para favorecer a formação de vínculos, conversavam a respeito da proposta do projeto e, em seguida, convidavam todos a se integrarem ao grupo. Dentre as atividades propostas, estavam: desenhos, comemorações de datas especiais e atividades temáticas (Dia dos Pais, Dia das Crianças, Páscoa, Natal, etc. ) artesanato; costura; trabalhos manuais; origami; confecção de painéis sobre temas escolhidos pelo próprio grupo, como, por exemplo, a importância do apoio da família no decorrer da hospitalização da criança; confecção de brinquedos e enfeites para berços; relaxamento; dança; brincadeiras; dinâmicas de grupo que possibilitassem a expressão dos sentimentos dos acompanhantes, sendo estas últimas representadas por desenhos que retratavam 0 momento vivido, e, em seguida, o grupo buscava desvendar seus significados. Músicas, em especial as relaxantes, eram escolhidas para os alongamentos, e havia ainda as atividades em oficinas em geral, com recortes em revistas e colagem. As atividades eram simples, porém atrativas e possibilitavam a integração de um maior número possível de pessoas que, com criatividade e brincadeiras, conviviam em um ambiente descontraído e agradável.

Como já descrito anteriormente, os objetivos do projeto de extensão estão direcionados ao desenvolvimento de atividades lúdicas com familiares e acompanhantes de crianças hospitalizadas. Contudo, em alguns encontros, contamos com a participação de um número expressivo de crianças hospitalizadas, que passaram a acompanhar e incentivar seus responsáveis nas atividades e a demonstrar satisfação por terem sido incorporadas ao trabalho. Dessa forma, observamos que o projeto de extensão tem contribuído, também, para o fortalecimento das relações entre a criança e seus responsáveis, facilitando o processo de hospitalização.

Durante os encontros, pudemos observar 0 estreitamento de laços entre familiares/acompanhantes e crianças, que dispendiam juntos seu tempo fazendo 
as atividades e, muitas vezes, precisavam do auxílio do outro para finalizar seus trabalhos. Além disso, os membros do grupo pediam opiniões uns para os outros e elogiavam os resultados obtidos; isso criava e intensificava os laços de amizade, favorecidos pela reunião de pessoas que vivenciavam situações semelhantes, em um local comum.

Contudo, algumas atividades planejadas para os familiares/acompanhantes não contemplavam 0 envolvimento das crianças, como as dinâmicas de grupo; nelas, os familiares priorizavam a discussão de sentimentos oriundos da experiência de hospitalização dos filhos. Nessas ocasiões, precisamos deslocar uma das alunas de graduação para realizar um outro tipo de atividade com as crianças; desenhos, rodas de leitura, dentre outras, adequação que foi de fundamental importância para o desenvolvimento do projeto, pois tanto os participantes quanto as crianças sentiam-se mais seguros por estarem no mesmo ambiente.

Eram freqüentes as situações em que as mães mostravam receio de iniciar as atividades; referiam que não conseguiriam bom desempenho com trabalhos manuais ou que não estavam acostumadas a tarefas que exigissem criatividade. A grande maioria mostravase surpresa com os resultados obtidos em seus trabalhos e com o próprio desenvolvimento, e essa conquista a motivava para novos encontros. Além disso, muitas verbalizavam satisfação por estarem participando das atividades, pois aquela era uma oportunidade para distração, entretenimento e descontração, mesmo com tantas dificuldades vivenciadas no ambiente hospitalar.

Durante os encontros, os participantes conversavam entre si e com os integrantes do projeto de extensão, compartilhavam angústias, dificuldades e tristezas, encontrando apoio e motivação no grupo. Ocorriam, também, discussões entre eles, promovendo um espaço oportuno e acolhedor para comunicar o que fosse necessário e importante para eles naquele momento.

0 relato dos participantes, em relação aos benefícios advindos com a realização das atividades do projeto de extensão, extrapolou o momento de lazer vivenciado no ambiente hospitalar. Relataram que muito do que aprenderam naquele espaço era aproveitado de diversas formas, seja pelo modo como a criança se reaproximava da família no momento do retorno ao lar, mostrando os desenhos e os objetos que produziu durante a hospitalização, seja presenteando as pessoas com sua produção. Relataram, ainda, que o aprendizado resultante da participação no projeto constituiu-se numa fonte de renda para a família; muitos conseguiram comercializar diversos artigos confeccionados por eles, nas oficinas.
Em virtude da cronicidade apresentada pela maioria das crianças hospitalizadas na referida clínica, que exigia internações longas e freqüentes, passamos a conhecê-las melhor, bem como a seus familiares, ao longo da nossa atuação no grupo. Essa possibilidade de estreitamento de relações fez com que as mães, ao retornarem para reinternação de suas crianças, prontamente procurassem conhecer 0 andamento das atividades de lazer dos últimos encontros e quais as atividades futuras. Pela própria doença, algumas crianças retornavam para internações em clínicas específicas e, para nossa satisfação, como as mães já conheciam as datas e horários dos encontros, deslocavam-se de seus respectivos andares para participarem das atividades ou até mesmo apenas para reencontrarem o grupo.

\section{AS DIFICULDADES ENCONTRADAS}

Mesmo contando com esforços positivos e respostas acolhedoras dos participantes, durante 0 desenvolvimento do projeto, enfrentamos algumas dificuldades. A primeira barreira foi a falta de um local apropriado para a realização das atividades, visto que, conforme o planejamento, precisávamos de um ambiente com mesas e cadeiras em quantidade adequada e que ainda acolhesse confortavelmente todos os familiares/acompanhantes, crianças e os próprios graduandos. O local mais apropriado, como já relatado, foi o refeitório da Clínica; no entanto, foi necessário adequar os horários das atividades para que não coincidissem com o momento do jantar. Assim, esperávamos o término das refeições para darmos início às atividades propostas para cada encontro.

Outra dificuldade foi a falta de financiamento específico para a compra de materiais, o que limitou, algumas vezes, as atividades aos recursos disponíveis, ou então não nos deixou atender às expectativas dos participantes em relação à realização de atividades propostas por eles.

Observamos que, em alguns momentos, os familiares/acompanhantes e as crianças precisaram se deslocar para suas respectivas enfermarias, pois estas deveriam receber algum tipo de cuidado. Grande parte desses procedimentos consistia de verificações rotineiras de temperatura axilar das crianças, que poderiam ter sido feitas após o término das sessões, poupando os participantes de interrupções desnecessárias. $\quad \mathrm{Na}$ avaliação contínua do desenvolvimento das atividades do projeto de extensão, identificamos momentos em que a equipe de enfermagem poderia ter mostrado maior flexibilidade no desenvolvimento das rotinas de cuidado à criança, 
principalmente quando não se colocava em risco a sua saúde. Entendemos que dar à criança e a seus familiares/acompanhantes a oportunidade de participar das atividades do projeto de extensão faz parte do cuidado de enfermagem, uma vez que visa à promoção da saúde de todos os envolvidos ${ }^{14}$.

0 estado de saúde das crianças também foi um fator que contribuiu para que vários familiares não participassem de alguns encontros. Apesar do desejo, eles não se sentiam à vontade para integrar o grupo, tendo que deixar os filhos desacompanhados nas enfermarias, chorando por qualquer razão ou em situação delicada de saúde. Da mesma forma, era comum a permanência dos familiares/acompanhantes nas enfermarias, quando o tratamento das crianças requeria qualquer tecnologia de cuidado que não permitia o deslocamento das mesmas até o local onde se desenvolviam as atividades do projeto. Nessas ocasiões, deparamos, freqüentemente, com solicitações dos familiares/acompanhantes para que desenvolvêssemos as atividades dentro de uma determinada enfermaria; solicitação difícil de atender, pois não dispúnhamos de um número suficiente de recursos humanos para estender as atividades para outros espaços. Assim, a dificuldade enfrentada reside no fato de termos que lidar com as expectativas dos familiares/acompanhantes e não podermos atendêlas, devido aos limites de atuação.

Finalmente, o número reduzido de dinamizadores para o desenvolvimento do projeto de extensão constituise numa outra dificuldade, que só foi minimizada com a chegada de novos voluntários ao grupo. Contudo, mesmo contando com a valiosa colaboração destes últimos, urge ampliar o número de bolsistas do projeto.

\section{CONSIDERAÇÕES FINAIS}

A melhoria da qualidade do atendimento às crianças e suas famílias é objetivo da nossa prática profissional e, especialmente, deste projeto de extensão. Por seu intermédio, procuramos facilitar a inserção e a participação dos pais e outros familiares/ acompanhantes no cuidado às crianças hospitalizadas, visando a diminuir, principalmente, o ócio vivenciado por esta clientela no hospital. Para tanto, canalizamos todos os esforços no planejamento e desenvolvimento de atividades de lazer que pudessem minimizar os efeitos adversos do processo de hospitalização. Este trabalho oferece uma recompensa diária, com resultados visíveis a cada etapa finalizada, e, ainda, descobertas de como os familiares, especialmente as mães, vivenciam o impacto da doença de seus filhos e como lidam com isso no dia-a-dia.

A operacionalização do projeto de extensão mostrou-se bastante favorável, como estratégia de intervenção de enfermagem, uma vez que contribuiu para o oferecimento de uma assistência holística aos familiares e acompanhantes da criança hospitalizada. 0 projeto apóia-se na compreensão de que o espaço hospitalar não é um local onde se vivenciam apenas aspectos desagradáveis, como dor, medo, ansiedade e estresse; ao contrário, pode ser transformado em um local de alegria e descontração, e isso pode melhorar a qualidade de vida não apenas da criança hospitalizada, mas também de seus familiares e acompanhantes, já que todos participam, direta ou indiretamente, do processo. 0 projeto contribuiu, também, para 0 desenvolvimento de ações de humanização comumente discutidas na prática de profissionais de saúde, pois levou em conta a proposta elaborada pelo Programa Nacional de Humanização da Assistência Hospitalar do Ministério da Saúde ${ }^{15}$.

Ao olharmos a intervenção operacionalizada com as atividades de lazer, podemos afirmar que ela promoveu mudança no dia-a-dia dos participantes, porque o lazer tornou o ambiente mais acolhedor, permitiu a interação entre familiares e acompanhantes das diversas crianças hospitalizadas e, ainda, tornou oportuno o preenchimento do tempo ocioso com brincadeiras e sorrisos, o que promoveu a saúde dos participantes, por meio da arte e da criatividade.

Além dos aspectos positivos aqui relatados, que beneficiaram os familiares e acompanhantes da criança hospitalizada, destacamos a importância do papel da Universidade na realização deste tipo de atividade de extensão de serviço à comunidade e a oportunidade que os graduandos, bolsistas e voluntários, puderam vivenciar, ampliando sua formação acadêmica e profissional. Tal importância pode ser medida pelo número crescente de voluntários (doze) que integraram as atividades do projeto dia a dia e as realizaram com grande dedicação, desde a sua implantação até 0 presente momento.

Assistir a criança e o adolescente hospitalizados da forma menos traumática possível é nossa principal meta, e este cuidado só pode ser atingido se estendermos nossas ações também às suas famílias. Integrar os pais, familiares e acompanhantes às enfermarias de pediatria e permitir que estes participem de forma positiva do cuidado dispensado ao filho, proporcionando-lhes, inclusive, lazer, pode trazer resultados bastante significativos na vida de todos os envolvidos neste processo. 


\section{Referências}

1. Oliveira I, Ângelo M. Vivenciando com o filho uma passagem difícil e reveladora: a experiência da mãe acompanhante. Rev Esc Enferm USP 2000 jun; 34(2): 202-08.

2. Oliveira BRG, Collet N. Criança hospitalizada: percepção das mães sobre o vínculo afetivo criança-família. Rev Latino-Am Enfermagem 1999 dez; 7(5): 95-102.

3. Cristo RC. A inserção do acompanhante em unidade de internação pediátrica no Distrito Federal [dissertação de mestrado]. Ribeirão Preto (SP): Escola de Enfermagem de Ribeirão Preto/USP; 1999.

4. Darbyshire P. Living with a sick child in hospital: the experiences of parents and nurses. London(UK): Chapman \& Hall; 1994

5. Lima RAG, Rocha SMM, Scochi CGS. Assistência à criança hospitalizada: reflexões acerca da participação dos pais. Rev LatinoAm Enfermagem 1999 abr; 7(2): 33-9.

6. Lei nº 8.069 de 13 de julho de 1990. Dispõe sobre o Estatuto da Criança e do Adolescente e dá outras providências. Diário Oficial da Republica Federativa do Brasil, Brasilia (DF), 14 de julho 1990: cap. 1.

7. Resolução nº 41 de 13 outubro de 1995. Dispõe sobre os direitos da criança e do adolescente hospitalizados. Diário Oficial da Republica Federativa do Brasil, Brasilia (DF) 17 de outubro de 1995: Seção 1.

8. Resolução nSS-165. Dispõe sobre adoção do Programa da "Mãe Participante" nos estabelecimentos que específica e dá providência correlatada. Diário Oficial do Estado de São Paulo, 14 de março de 1989: Seção 1.

9. Palmer SJ. Care of sick children by parents: meaningful role. J Adv Nurs 1993 Feb; 18 (2):185-91.

10. Kristensson-Hallström I, Elander G, Malmfors G. Increased parental participation in a paediatric surgical day care unit. I Clin Nurs 1997 July; 6(4): 297-302.

11. Collet N, Rocha SMM. Relação entre pais e enfermeiros no cuidado à criança hospitalizada: um ensaio crítico. Esc Anna Nery Rev Enferm $2000 \mathrm{abr} ; 4$ (1): 55-66.

12. Collet N, Oliveira BRG. Criança hospitalizada sem acompanhante: experimentando o sofrimento. Texto \& Contexto Enferm 1998 maio/ ago; 7(2): 255-67.

13. Brunherotti MR, Pereira FL, Souza MI, Nogueira FS, Scochi CGS. Lazer para pais de bebês de risco: a experiência junto ao Hospital das Clínicas de Ribeirão Preto. Rev Bras Enferm 2000; 53(3): 339-40.

14. Bomar PJ. Promoting health in families: applying family research and theory to nursing practice. Philadelphia(USA): Saunders; 2004.

15. Ministério da Saúde (BR). HumanizaSUS.Política Nacional de Humanização. [on line] 2005 [citado 16 nov 2005]. Disponível em: http://portal.saude.gov.br/portal/arquivos/pdf/doc_base.pdf.

\section{Nota}

aProjeto inserido no Grupo de Estudos em Saúde da Criança e do Adolescente, da Escola de Enfermagem de Ribeirão Preto da Universidade de São Paulo (EERP-USP), Centro Colaborador da OMS para o Desenvolvimento da Pesquisa em Enfermagem. Departamento de Enfermagem Materno-Infantil e Saúde Pública.

\section{Sobre as Autoras}

\section{Lucila Castanheira Nascimento}

Coordenadora do Projeto, Prof. ${ }^{a} \mathrm{Dr}^{\mathrm{a}}$. da EERP-USP.

\section{Paula de Siqueira Furquim}

Aluna do $8^{\circ}$ semestre do Curso de Graduação em Enfermagem da EERP-USP, Bolsista PIBIC/CNPq. Agradecemos ao Conselho Nacional de Desenvolvimento Científico e Tecnológico - CNPq, pela concessão de bolsa de iniciação científica.

\section{Ariane Ranzani Rigotti}

Aluna do $6^{\circ}$ semestre do Curso de Graduação em Enfermagem da EERP-USP, Bolsista COSEAS/USP.

\section{Flávia Mendonça Rosa Luiz}

Membro integrante do Projeto.

Paula Saud de Bortoli

Membro integrante do Projeto.

\section{Silmara Gianoti}

Membro integrante do Projeto. 